\title{
miR-182-5p Promotes Growth in Oral Squamous Cell Carcinoma by Inhibiting CAMK2N1
}

\author{
Nan Li ${ }^{a}$ Chuan-Chuan Nan ${ }^{b}$ Xue-Yun Zhong ${ }^{c}$ Jun-Quan Weng ${ }^{a}$ Hai-Dong Fan ${ }^{a}$ \\ Hai-Peng Sun ${ }^{\mathrm{a}}$ Su Tang ${ }^{\mathrm{a}}$ Lei Shi ${ }^{\mathrm{a}}$ Sheng-Xing Huanga \\ aDepartment of Stomatology Center, Shenzhen People's Hospital, Second Clinical Medical School of \\ Jinan University, Shenzhen, 'Department of Intensive Care Unit, Shenzhen People's Hospital, Second \\ Clinical Medical School of Jinan University, Shenzhen, 'Basic Medical School of Jinan University, \\ Guangzhou, China
}

\section{Key Words}

Oral squamous cell carcinoma $\cdot$ MicroRNAs $\cdot$ CAMK2N1 Proliferation

\begin{abstract}
Background/Aims: Emerging evidence suggests that the propagation of oral squamous cell carcinoma (OSCC) is influenced by the abnormal expression of microRNAs (miRNAs). This study aimed to characterize the involvement of miR-182-5p in OSCC by targeting the calcium/ calmodulin-dependent protein kinase II inhibitor CAMK2N1. Methods: miR-182-5p expression was quantified in OSCC tissues and cell lines with reverse transcription polymerase chain reaction (RT-PCR). Cell colony formation, Cell Counting Kit-8 (CCK-8), Ki-67, and nude mouse xenograft assays were used to characterize the role of miR-182-5p in the proliferation of OSCC. A miR-182-5p target gene was identified with western blotting, RT-PCR, and luciferase activity assays. OSCC patient survival based on CAMK2N1 expression was also analyzed. Results: miR-182-5p was up-regulated in in vitro cell lines and in vivo clinical OSCC samples. CCK-8, colony formation, and Ki-67 assays revealed that miR-182-5p promoted the growth and proliferation of OSCC cells. miR-182-5p directly targeted CAMK2N1, as evidenced by luciferase assays and target prediction algorithms. CAMK2N1 operated as a tumor suppressor gene in patients with OSCC. Down-regulating miR-182-5p expression in the CAL-27 cell line restored CAMK2N1-mediated OSCC cell proliferation. miR-182-5p expression inhibited the activation of AKT, ERK1/2, and NF-KB. Mice injected with CAL-27 cells transfected with miR182-5p-inhibitor demonstrated a significant increase in tumor size and weight and increased CAMK2N1 mRNA and protein expression compared with the miR-negative control group. Conclusion: The miR-182-5p-CAMK2N1 pathway can be potentially targeted to regulate the proliferation of OSCC cells.

N. Li and C. Nan contributed equally to this work.




\section{Cellular Physiology Cell Physiol Biochem 2018;49:1329-1341 \begin{tabular}{l|l} 
DOI: 10.1159/000493411 & $\begin{array}{l}\text { O } 2018 \text { The Author(s). Published by S. Karger AG, Basel } \\
\text { www.karger.com/cpb }\end{array}$
\end{tabular}}

Li et al.: miR-182-5p Promotes Growth by Inhibiting CAMK2N1

\section{Introduction}

Oral squamous cell carcinoma (OSCC) represents over $90 \%$ of oral cavity cancers [1, $2]$, with a rapidly increasing incidence among young and middle-aged individuals due to excessive smoking and alcohol consumption [3]. Despite efforts to improve its early diagnosis and treatment, advanced OSCC still has an extremely poor 5-year survival rate of less than $63 \%$, mainly due to high recurrence rates brought about by its ability to invade local tissues and to metastasize [4]. Surgery remains the first-line treatment for a significant proportion of patients with OSCC [5]. However, surgical treatment may require partial tongue removal, leaving patients with severe oral dysfunction resulting in dysphagia and dysarthria. Hence, the quality of life of patients receiving surgery is low. More methods that enable its early diagnosis and treatment are much needed in OSCC. Studies have found that some cancer genes and tumor suppressor genes may be crucial in enhancing or initiating the development of OSCC. Nevertheless, the specific molecular pathways underlying the development of OSCC are still unclear [6-8]. Therefore, it is important to elucidate the genomic and epigenomic mechanisms participating in multistep carcinogenesis and the progression of OSCC.

A myriad of cellular processes, including differentiation, development, proliferation, and apoptosis, are dictated by microRNAs (miRNAs), which are small segments of non-coding RNAs $[9,10]$. By negatively regulating gene expression at the post-transcriptional level, these single-stranded RNAs can inhibit gene translation and trigger the direct degradation of target messenger RNAs (mRNAs) [11]. More than one-third of protein-coding genes are estimated to be under miRNA translational control, with a single miRNA able to regulate hundreds of protein-coding genes [12,13].

miR-182-5p is a highly conserved miRNA whose expression has been found to be increased in several malignant human cancers, such as glioblastoma, hepatocellular carcinoma, and breast and gastric cancer [14]. However, how miR-182-5p contributes to the proliferation of OSCC cells remains poorly characterized. We aimed to investigate how miR$182-5 p$ functions in the pathophysiology of OSCC, specifically with regard to its ability to enhance proliferation.

\section{Materials and Methods}

\section{Human-derived OSCC tumor samples}

Twenty human-derived OSCC tumor specimens complete with surrounding non-cancerous tissue were sampled between 2015 to 2017 at the First Affiliated Hospital of Harbin Medical University (Harbin, China). All tissues were taken prior to the initiation of radiotherapy or chemotherapy and were frozen immediately and store at $-80^{\circ} \mathrm{C}$ until required. Cytological and/or pathological evidence of OSCC diagnosis was available for each subject. Each patient provided written informed consent.

\section{Cell line culture}

Human normal oral epithelial keratinocytes (hNOK) along with OSCC cell lines of human origin (Tca8113, CAL-27, SCC-4, UM-1, and OSC-4) were procured from the Chinese Academy of Science Shanghai Cell Bank (Shanghai, China). All cells were cultured in RPMI 1640 medium or Dulbecco's modified Eagle's medium (HyClone Laboratories, Inc., Logan, UT), both supplemented with $10 \%$ fetal bovine serum (Invitrogen, Carlsbad, CA), $100 \mathrm{U} / \mathrm{mL}$ penicillin, and $100 \mu \mathrm{g} / \mathrm{mL}$ streptomycin in a humidified chamber of $5 \% \mathrm{CO}_{2}$ at $37^{\circ} \mathrm{C}$.

\section{miRNA and transfection protocol}

miR-182-5p-mimic, miR-182-5p-negative control (miR-NC), miR-182-5p-inhibitor, and CAMK2N1 expression vector were all purchased from Genechem (Shanghai, China). Lipofectamine $₫ 2000$ Transfection Reagent (Life Technologies, Gaithersburg, MD) was utilized for the transfection of all cells with the aforementioned miRNAs, following the manufacturer's protocol. 


\section{Cellular Physiology Cell Physiol Biochem 2018;49:1329-1341 \begin{tabular}{l|l|l} 
and Biochemistry Published online: 12 September, 2018 & $\begin{array}{l}\text { (c) } 2018 \text { The Author(s). Published by S. Karger AG, Basel } \\
\text { www.karger.com/cpb }\end{array}$ \\
\hline
\end{tabular}}

Li et al.: miR-182-5p Promotes Growth by Inhibiting CAMK2N1

\section{Dual luciferase reporter assay}

Wild-type CAMK2N1 (CAMK2N1-WT) and mutated CAMK2N1 (CAMK2N1-Mut) were both cloned into pMIR-REPORT Luciferase vectors (Ambion; Thermo Fisher Scientific, Waltham, MA). CAL-27 cells were seeded in 6-well plates and then transfected with both vectors using Lipofectamine 2000 (Invitrogen) for 48 h. The Dual Luciferase-Reporter 1000 Assay System (Promega, Madison, WI) was used to evaluate luciferase activity. Renilla activity was used for normalization.

\section{RNA extraction and quantitative real-time PCR}

TRIzol (Invitrogen) was used to extract total RNA according to the manufacturer's instructions. The expression levels of miR-182-5p were quantified with an miRNA-specific TaqMan MiRNA Assay Kit (Applied Biosystems, Foster City, CA). The results were normalized against the expression of U6 small nuclear RNA, with resultant data expressed as Log2-fold changes in relation to miR/U6 levels. miR-182-5p and U6 primers were designed by and purchased from RiboBio Co., Ltd. (Guangzhou, China). CAMK2N1 primer sequences were designed following the procedures described in Hafner et al. [15].

\section{Western blot analysis}

Protease inhibitors (Roche, Indianapolis, IN) in combination with mammalian protein (60-80 $\mu \mathrm{g})$ extraction reagent (Pierce, Rockford, IL) were utilized to extract protein from cell lysates and cancer tissues. Cell lysates were centrifuged at $13,000 \mathrm{rpm}$ for $15 \mathrm{~min}$ at $4{ }^{\circ} \mathrm{C}$. The protein concentration of each sample was measured using the BCA Protein Assay Kit (Pierce). Protein samples were separated in 10-12\% sodium dodecyl sulfate-polyacrylamide gels and transferred to nitrocellulose membranes (Pall Corporation, Port Washington, NY). Blocking buffer (5\% non-fat milk in phosphate-buffered saline) was used to block the membranes. All membranes were incubated for $1 \mathrm{~h}$ with a buffer at room temperature. Primary antibodies utilized included anti-CAMK2N1 (Cat. No. 5436S), anti-phosphorylated-ERK1/2 (Cat. No. 5436S), anti-ERK (Cat. No. 5436S), anti-AKT (Cat. No. 5741S), anti-phosphorylated-AKT (Cat. No. 5741S), anti-NF- $\mathrm{KB}$ (Cat. No. 3195S), anti-phosphorylated-NF-кB (Cat. No. 5741S), and anti- $\beta$-actin (Cat. No. 4967S) (all obtained from Cell Signaling Technology, Danvers, MA). These antibodies were diluted to 1:500 to 1:1000, incubated overnight with the membranes at $4^{\circ} \mathrm{C}$, and subsequently rinsed using Tris-buffered saline with Tween 20 . The next day, the membranes were incubated with 1:1000 dilutions of mouse or rabbit secondary antibodies (Cell Signaling Technology). An imaging system (LI-COR Biosciences, Lincoln, NE) was used to produce blot images, while band densities were analyzed with Odyssey 3.0 software using $\beta$-actin as the standard.

\section{Cell viability assay}

A Cell Counting Kit-8 (CCK-8) assay (Beyotime Institute of Biotechnology, Beijing, China) was utilized to assess CAL-27 cell viability according to the manufacturer's protocols. Briefly, transfected CAL-27 cells were transferred to 96-well plates (3000 cells/well). After incubation for $2 \mathrm{~h}$ in $10 \mu \mathrm{L}$ CCK-8, the absorbance in each well was evaluated at $450 \mathrm{~nm}$ (Tecan Infinite M200 Micro Plate Reader; LabX, Männedorf, Switzerland). All experiments were repeated at least three times.

\section{Colony formation assay}

The cells were seeded in 60-mm dishes (800 cells/dish) and grown for 10 days. The culture medium was replenished after the $5^{\text {th }}$ day. The generated cells were methanol-fixed and stained for 10 min with $0.5 \%$ crystal violet. All samples were photographed, and the number of visible colonies was counted.

\section{Kaplan-Meier data analysis}

All of the clinical data and Tier 3 RNASeqV2 mRNA expression data were downloaded from The Cancer Genome Atlas (https://tcga-data.nci.nih.gov/tcga/). Patients with a follow-up time or time to death greater than 0 days were kept for analysis. For each gene, all samples were divided into two groups based on the median expression value of the respective gene. Kaplan-Meier analysis was performed to test the significance between both groups. Cox proportional hazards regression was also performed with the coxph function from the R survival library. Hazard ratios with 95\% confidence intervals were obtained. 


\section{Cellular Physiology Cell Physiol Biochem 2018;49:1329-1341 \begin{tabular}{l|l|l} 
and Biochemistry Published online: 12 September, 2018 & $\begin{array}{l}\text { (c) } 2018 \text { The Author(s). Published by S. Karger AG, Basel } \\
\text { www.karger.com/cpb }\end{array}$
\end{tabular}}

\section{Immunofluorescence assay}

CAL-27 cells were seeded on cover slips with different treatments. After $48 \mathrm{~h}$, the cells were fixed and incubated with an anti-Ki-67 antibody (Cell Signaling Technology) for $1 \mathrm{~h}$ and incubated with Alexa-488 at room temperature for $20 \mathrm{~min}$. The cells were counterstained with DAPI for nuclei. All cover slips were mounted using ProLong ${ }^{\circledR}$ Diamond Antifade Mountant (Thermo Fisher Scientific).

\section{Tumor xenograft nude mouse model}

CAL-27 cells were transfected with either miR-182-5p-inhibitor or miR-NC. CAL-27 cells $\left(5.0 \times 10^{6}\right.$ cells) were injected subcutaneously into the back of 6-week-old male BALB/c nude mice (Vital River Laboratory Animal Technology, Beijing, China) ( $n=6 /$ group) to generate OSCC tumors. Tumor volumes were measured using the formula: $\mathrm{V}=\pi / 6 \times \mathrm{L} \times \mathrm{S}^{2}$, where $\mathrm{L}$ and $\mathrm{S}$ are the long and short diameter, respectively. A tumor growth curve was constructed twice a week to determine the effects of the miR-182-5p-inhibitor and miR-NC on tumor growth. After 21 days, the mice were sacrificed. Tumors in each group were dissected and weighed. Total protein and RNA were extracted from the tumors for western blotting and quantitative real-time PCR (qRT-PCR).

\section{Statistical analysis}

Data are presented as the mean \pm standard deviation (SD). Comparisons between two groups were performed using the $t$-test, while analysis of variance was used for comparisons involving more than two groups and among groups. Pearson correlation analysis was also performed. $P$-values less than 0.05 were determined to be significant. All statistical calculations were conducted using SPSS software version 19 (SPSS, Inc., Chicago, IL).

\section{Results}

miR-182-5p expression in OSCC

OSCC tissue samples were examined to determine the expression levels of miR-182-5p. miR-182-5p expression was up-regulated in tumor samples compared with healthy adjacent tissue (Fig. 1A). Similarly, miR-182-5p expression was also found to be increased in OSCC cell lines (SCC-4, CAL-27, Tca8113, UM-1, and OSC-4) in contrast to hNOK bronchial epithelial cells (Fig. 1B).

\section{miR-182-5p regulates $O S C C$ cell viability}

The CCK-8 assay was used to determine the viability of CAL-27 cells transfected with either miR-182-5p-mimic or -inhibitor. CAL-27 cellular proliferation was inhibited when miR-182-5p was knocked down. On the other hand, miR-182-5p over-expression increased CAL-27 cell viability (Fig. 2A). Cell colony formation assays indicated similar patterns in

Fig. 1. miR-182-5p expression in OSCC. Relative miR-182$5 p$ expression levels in tumor samples ( $n=20$ ) from OSCC patients (A) and in OSCC cell lines (B). Data are presented as the mean \pm SD of three independent experiments. ${ }^{*} \mathrm{p}<0.05$ vs. normal group or hNOK group.

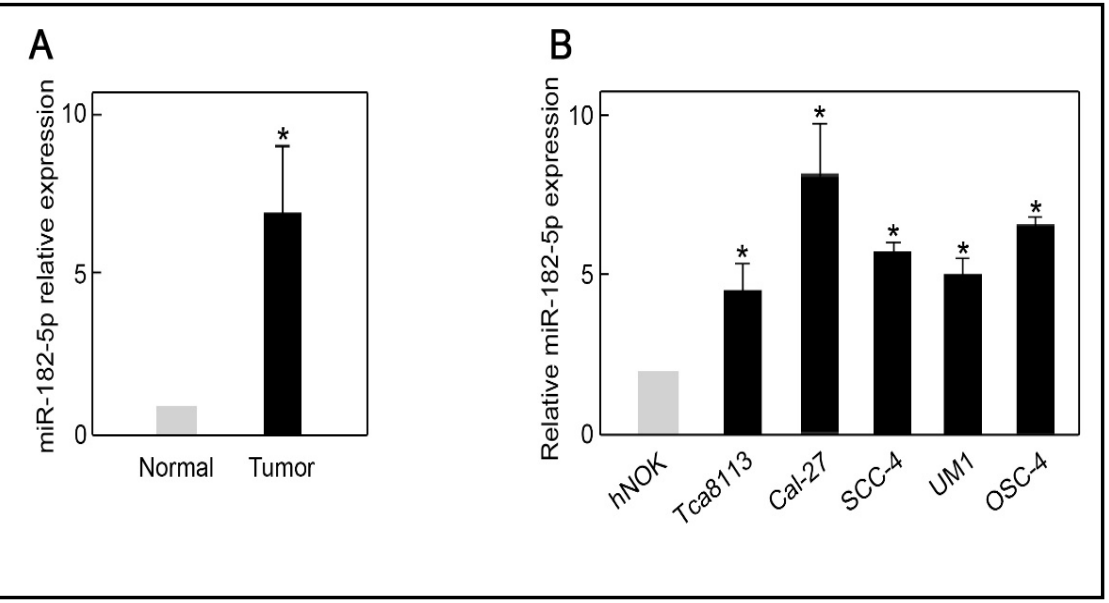


transfected CAL-27 colonies. Colony formation was inhibited in the miR-182-5p-inhibitor group, but was promoted in the miR-182-5p-mimic group (Fig. 2B). Likewise, the Ki-67 assay revealed a decrease in CAL-27 cell proliferation in the miR-182-5p-inhibitor group (Fig. 2C). Interpreted together, these data indicate that miR-182-5p is a negative regulator of CAL-27 cell proliferation.

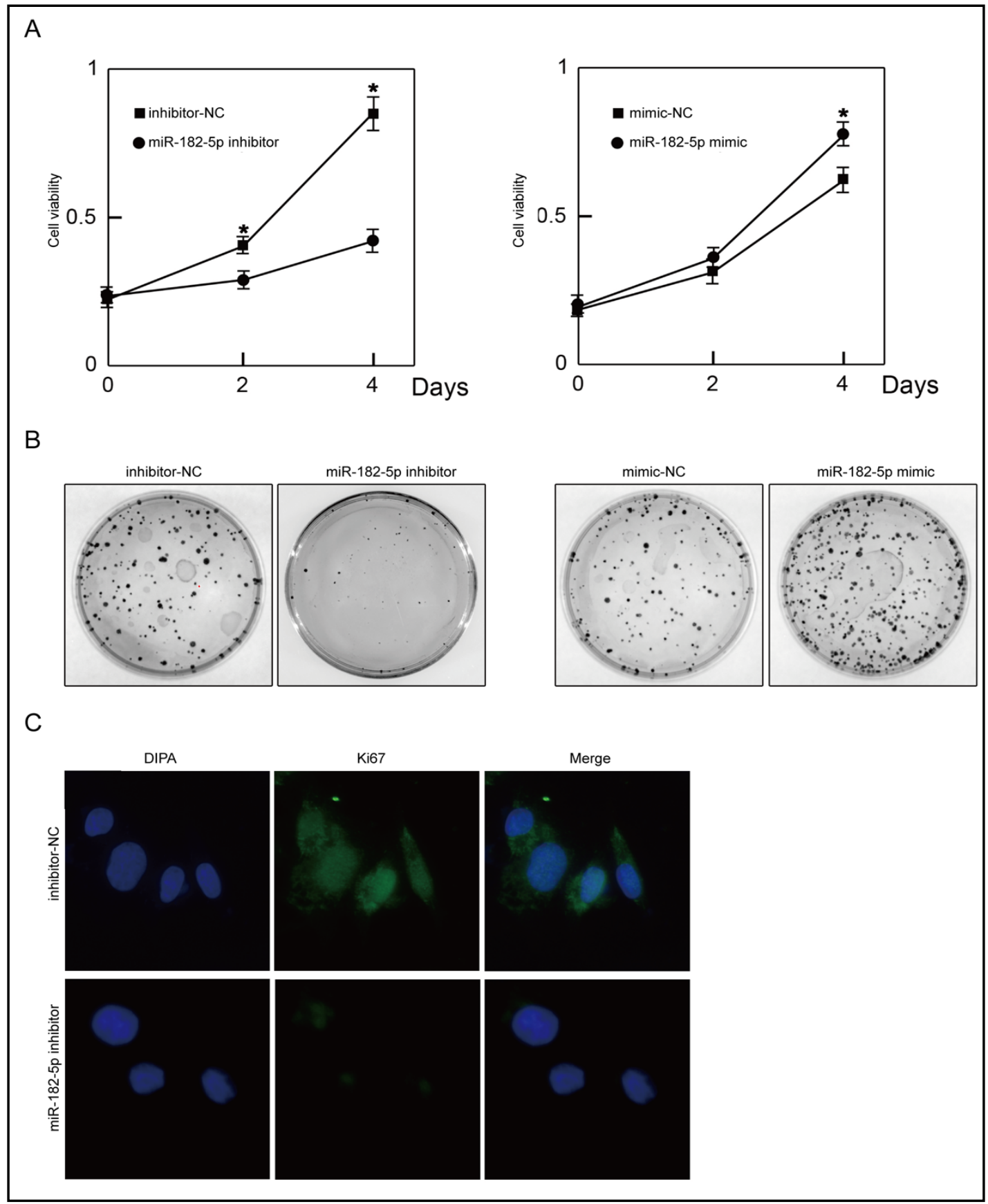

Fig. 2. miR-182-5p regulates OSCC cell viability. CCK-8 assay showing CAL-27 cell viability post-transfection with miR-182-5p-mimic or -inhibitor (A). Cell colony formation assay showing CAL-27 cell viability posttransfection with miR-182-5p-mimic or -inhibitor (B). Ki-67 assay showing CAL-27 cell viability after transfection with miR-NC or miR-182-5p-inhibitor (C). Data are presented as the mean \pm SD of three independent experiments. ${ }^{*} \mathrm{p}<0.05$ vs. miR-NC group. 
CAMK2N1 is a direct target of miR-182-5p in CAL-27 cells

We attempted to identify genes targeted by miR-182-5p in CAL-27 cells. CAMK2N1 expression was examined in both OSCC patients and cell lines (Fig. 3A, B). Overall survival times (as determined by Kaplan-Meier analysis) were markedly longer in patients that had elevated CAMK2N1 expression compared with patients with negative or low CAMK2N1 expression (Fig. 3C). Additionally, we found that CAMK2N1 protein and mRNA levels were up-regulated in miR-182-5p-inhibitor cells in contrast to miR-NC cells (Fig. 3D, E). Moreover, cell transfection with the miR-182-5p-mimic down-regulated CAMK2N1 mRNA and protein levels. Subsequent bioinformatics analysis (using www.targetscan.org) revealed that there was a putative binding site for miR-182-5p in the $3^{\prime}$-untranslated region (3'-UTR) of CAMK2N1 mRNA (Fig. 3F). We also found that co-transfection with miR-182-5p-mimics/ CAMK2N1-WT significantly reduced luciferase activity, while co-transfection with miR-1825p-inhibitor/CAMK2N1-WT increased luciferase activity (Fig. 3G). On the basis of these findings, we are able to conclude that miR-182-5p directly targets CAMK2N1.

\section{CAMK2N1 regulates CAL-27 cell viability}

The CCK-8 assay revealed that the viability of CAL-27 cells was increased in cells transfected with CAMK2N1-siRNA and decreased in cells over-expressing CAMK2N1 (Fig. 4A) compared with the control group. The colony formation assay also showed that CAMK2N1-siRNA promoted cell proliferation, while over-expressing CAMK2N1 inhibited cell proliferation (Fig. 4B). Likewise, the Ki-67 assay revealed an increase in CAL-27 cell

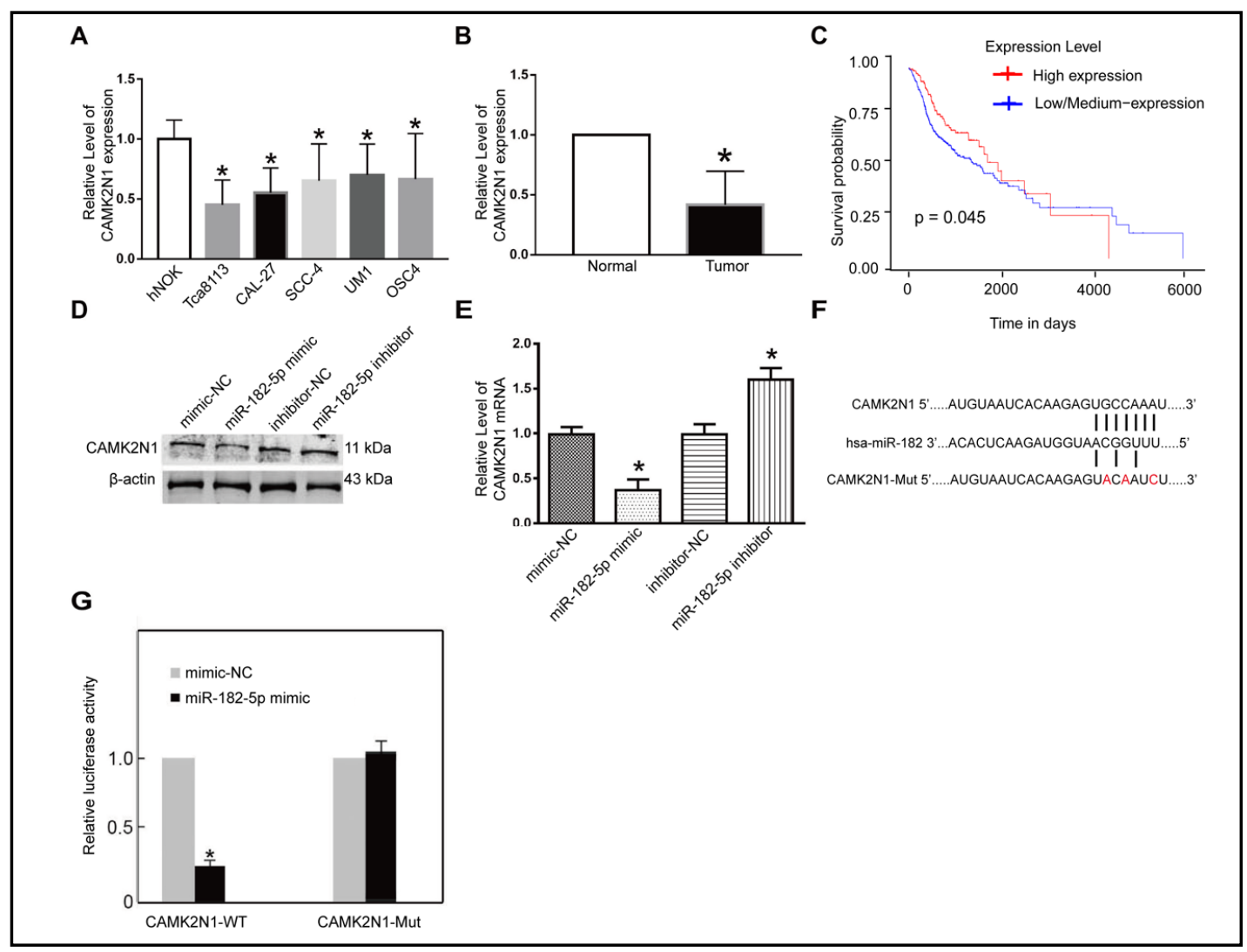

Fig. 3. CAMK2N1 is a direct target of miR-182-5p in CAL-27 cells. Relative gene expression levels of CAMK2N1 in OSCC cell lines (A) and tumor samples from OSCC patients (B). Kaplan-Meier survival (C) and protein (D) and mRNA (E) levels of CAMK2N1 after transfection with miR-182-5p. miR-182-5p-binding site in the 3'-UTR of human CAMK2N1 mRNA (F). Luciferase assay in CAL-27 cells (G). Data are presented as the mean \pm SD of three independent experiments. ${ }^{*} \mathrm{p}<0.05$ vs. the other group. 
proliferation in the CAMK2N1-siRNA group, but this was inhibited by CAMK2N1 overexpression (Fig. 4C). Interpreted together, these data indicate that CAMK2N1 is an important regulator of CAL-27 cell proliferation.

Co-transfection of CAL-27 cells with miR-182-5p-inhibitor/CAMK2N1-siRNA restores cell growth

To confirm if miR-182-5p targeting of CAMK2N1 promoted CAL-27 cell proliferation, CAL-27 cells were co-transfected with CAMK2N1-siRNA and miR-182-5p-inhibitor. We first quantified miR-182-5p and CAMK2N1 mRNA and protein levels (Fig. 5A, B). The CCK-8 assay validated that co-transfection with CAMK2N1-siRNA/miR-182-5p-inhibitor restored the regenerative capability of CAL-27 cells (Fig. 5C). Colony formation and Ki-67 assays also confirmed that CAL-27 cell viability was restored by co-transfection with miR-1825p-inhibitor/CAMK2N1-siRNA (Fig. 5D, E). Our findings indicate that miR-182-5p-targeted CAMK2N1 is responsible for regulating the growth of CAL-27 cells.

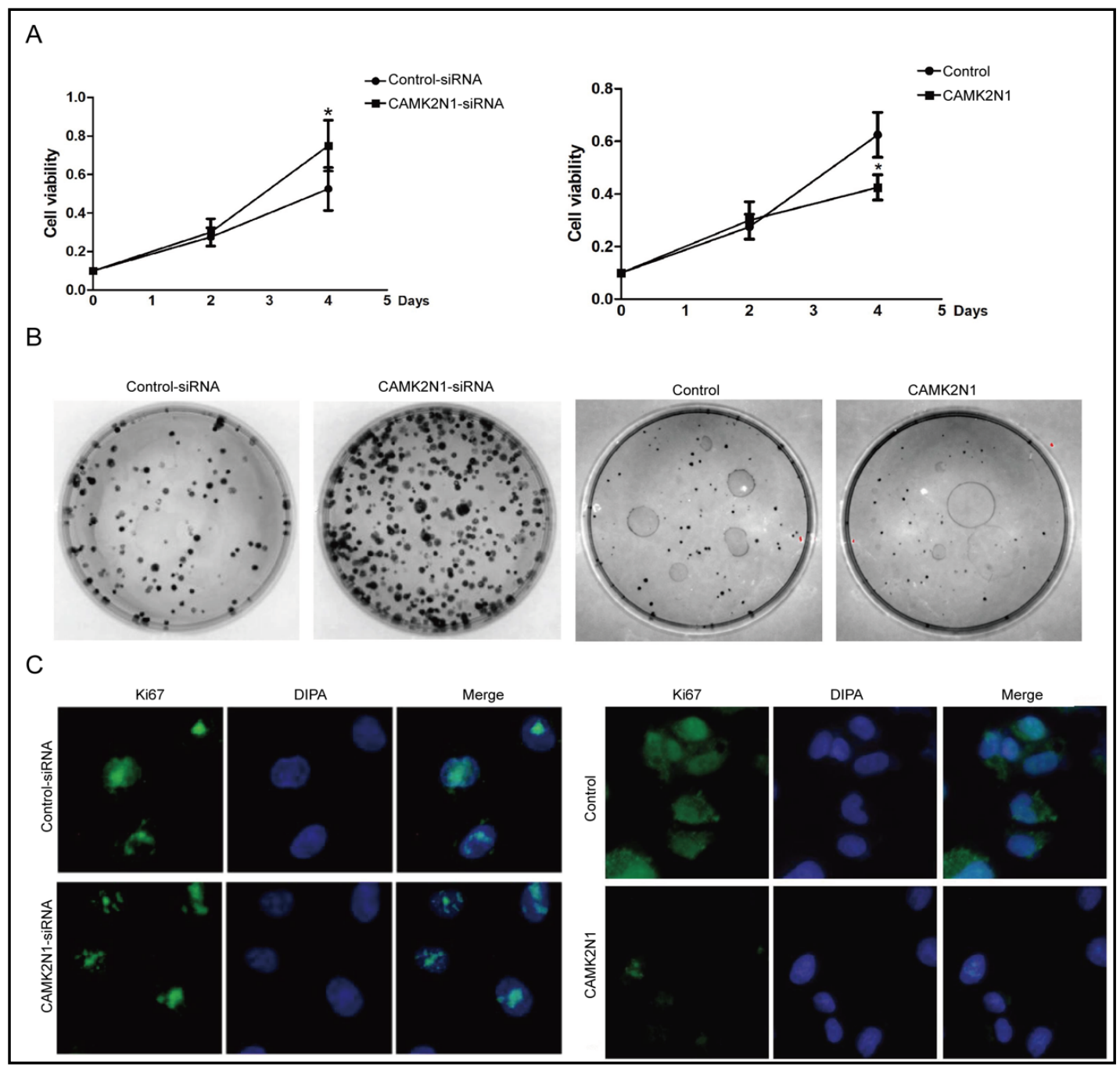

Fig. 4. Silenc CAMK2N1 reduces the viability of CAL-27 cells. CCK-8 assay showing CAL-27 cell viability post-transfection with CAMK2N1-siRNA or control-siRNA and over-expression of CAMK2N1 (A). Cell colony formation assay showing CAL-27 cell viability post-transfection with CAMK2N1-siRNA or over-expression of CAMK2N1 (B). Ki-67 assay showing CAL-27 cell viability after transfection with CAMK2N1-siRNA or over-expression of CAMK2N1 (C). Data are presented as the mean \pm SD of three independent experiments. ${ }^{*} \mathrm{p}<0.05$ vs. control group.

\section{KARGER}




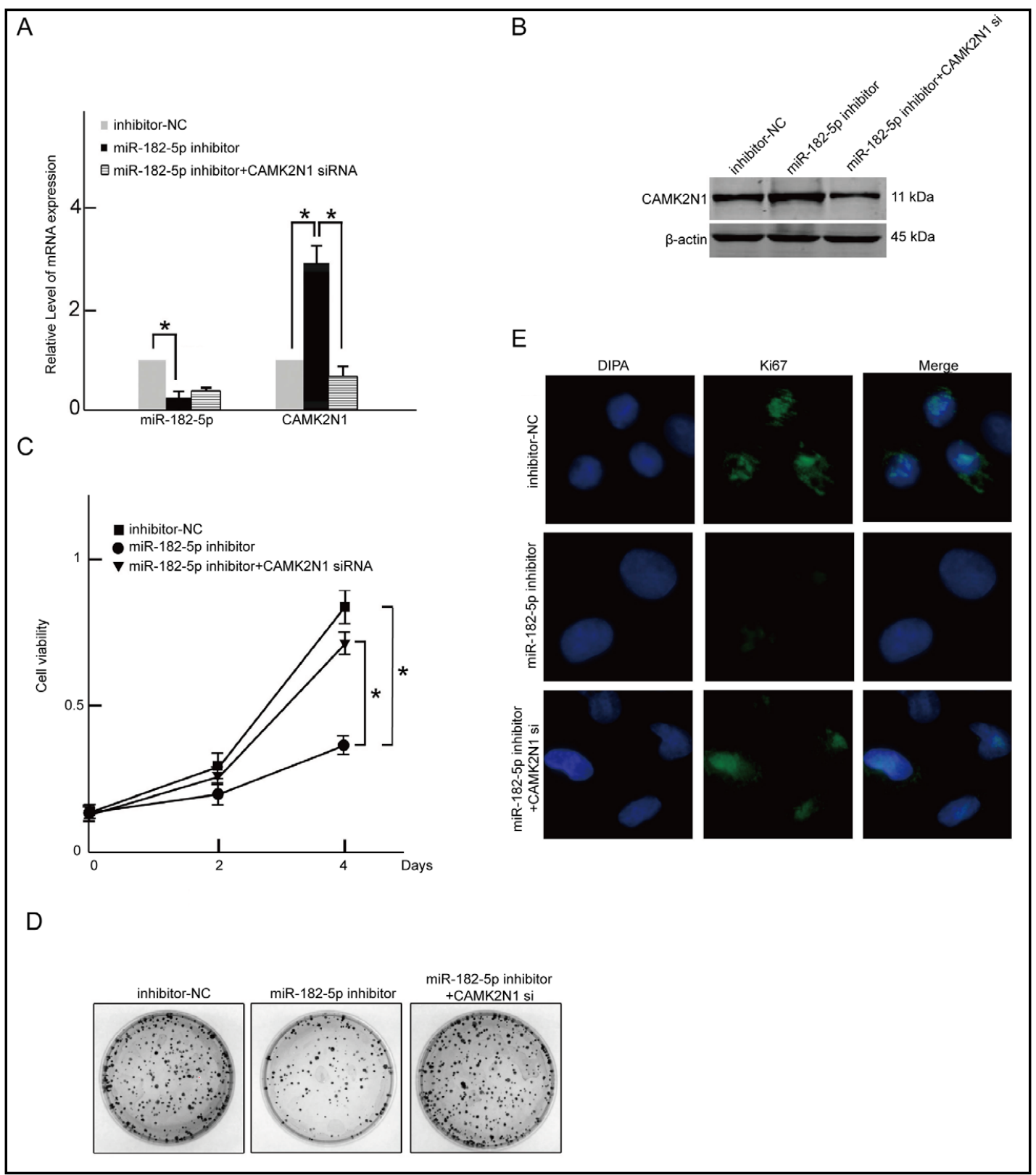

Fig. 5. Co-transfection of CAL-27 cells with miR-182-5p-inhibitor and CAMK2N1-siRNA restores cell growth. The relative levels of miR-182-5p and CAMK2N1 mRNA (A) and protein (B) were evaluated in CAL27 cells co-transfected with miR-182-5p-inhibitor and CAMK2N1-siRNA. CCK-8 (C), cell colony (D), and Ki67 (E) assays were performed in CAL-27 cells transfected with miR-NC, miR-182-5p-inhibitor, and miR-182$5 p$-inhibitor + CAMK2N1-siRNA. Data are presented as the mean \pm SD of three independent experiments. $* \mathrm{p}<0.05$ vs. the other group.

miR-182-5p expression inhibits AKT, ERK1/2, and NF- $k B$ activation

miR-182-5p-mimic-transfected CAL-27 cells were used for protein quantification. Western blot analysis showed that the phosphorylation of AKT, ERK1/2, and NF- $\mathrm{BB}$ was enhanced in CAL-27 cells treated with miR-182-5p-mimic (Fig. 6A-C), and diminished in cells transfected with miR-182-5p-inhibitor (Fig. 6D, E). 


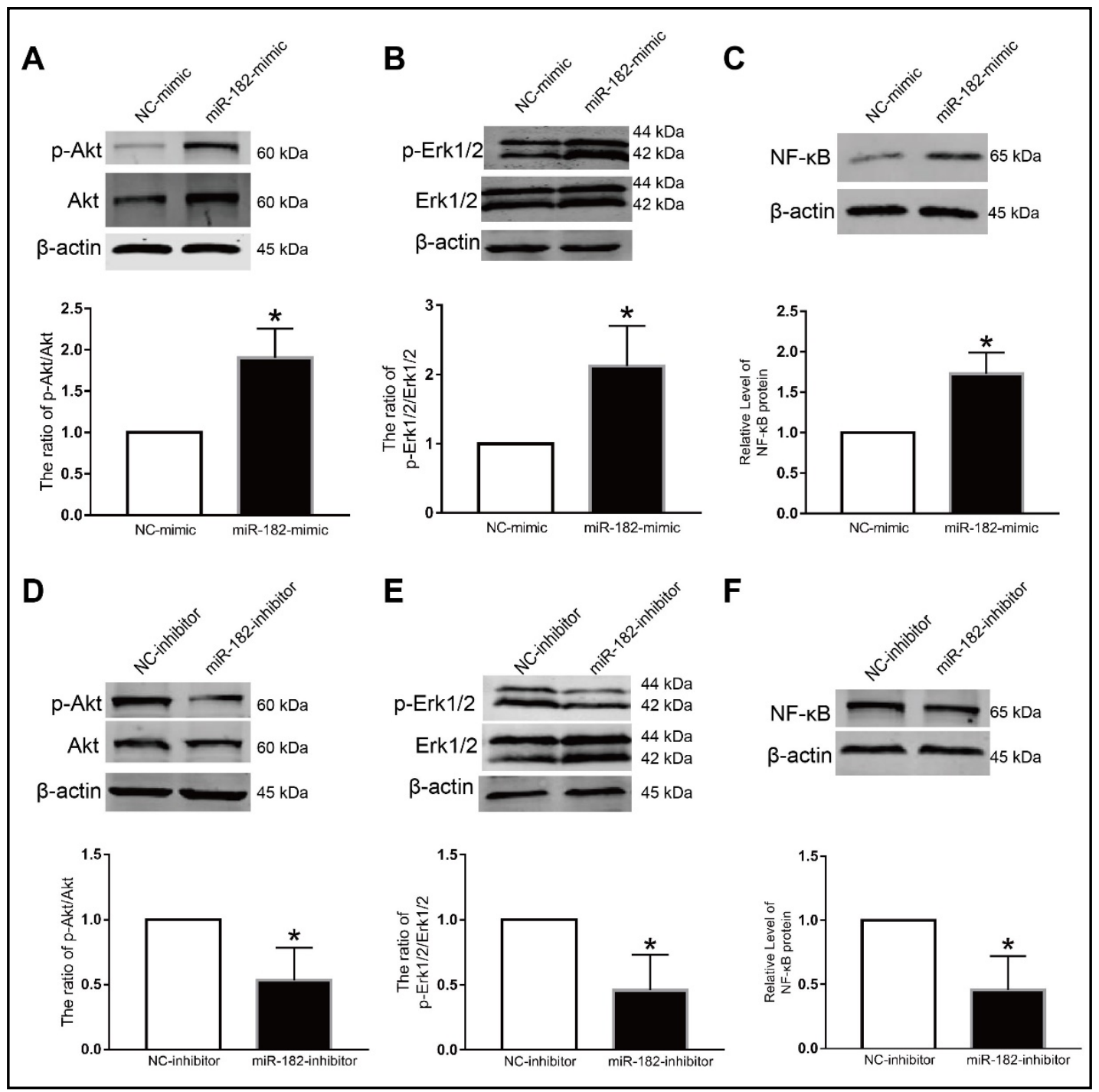

Fig. 6. miR-182-5p regulates AKT, ERK1/2, and NF- $\kappa B$ activation. Western blot demonstrating the protein levels of AKT and phosphorylated (p)-AKT (A), ERK1/2 and p-ERK1/2 (B), and NF- $\mathrm{B}$ (C) in human CAL27 cells transfected with miR-182-5p-mimic or miR-NC. The protein levels of AKT and p-AKT (D), ERK1/2 and p-ERK1/2 (E), and NF- $\mathrm{B}(\mathrm{F})$ in human CAL-27 cells transfected with miR-182-5p-inhibitor or miR-NC. ${ }^{*} \mathrm{p}<0.05$ vs. negative control group.

\section{miR-182-5p downregulation inhibits tumor growth in vivo}

To investigate further how miR-182-5p modulates tumor proliferation in vivo, we employed the use of a xenograft model of human CAL-27 cell transplantation in nude mice. Mice injected with CAL-27 cells transfected with miR-182-5p-inhibitor demonstrated significant decreases in tumor size and weight compared with the miR-NC group (Fig. 7A-C). Meanwhile, immunoblotting assays indicated that CAMK2N1 mRNA was expressed at a higher level in tumor tissues from mice in the miR-182-5p-inhibitor group compared with tissues from the mice in the miR-NC group (Fig. 7D). Similar trends were observed for CAMK2N1 protein expression (Fig. 7E). In conclusion, these findings indicate that miR-182$5 p$ operates as a tumor suppressor in OSCC. 


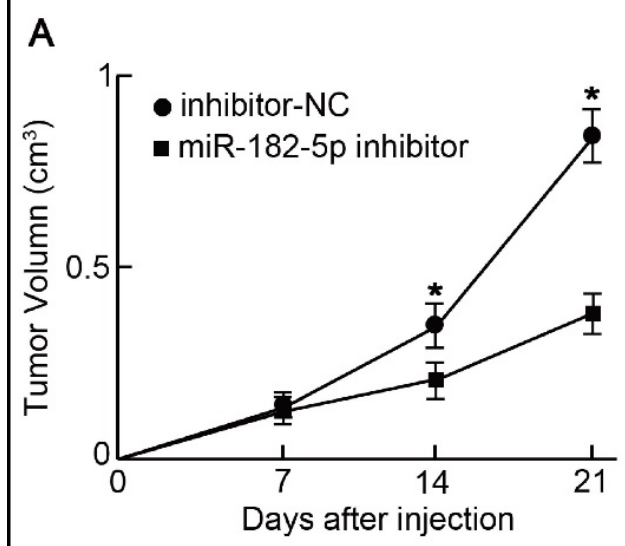

C
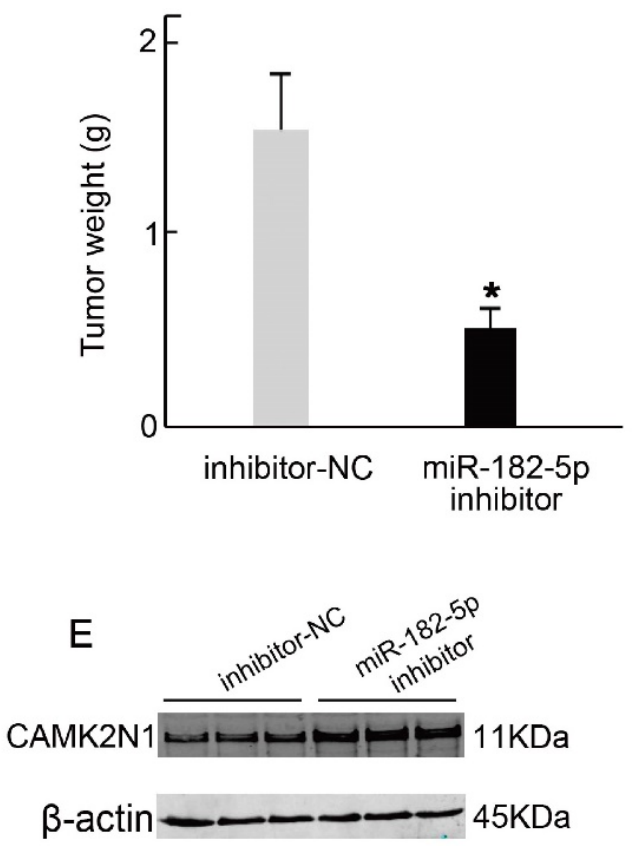

B

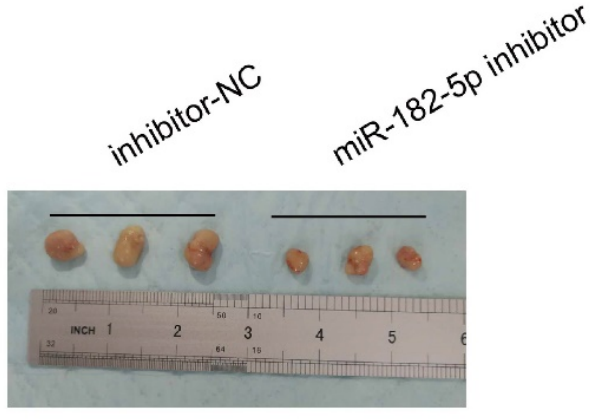

D

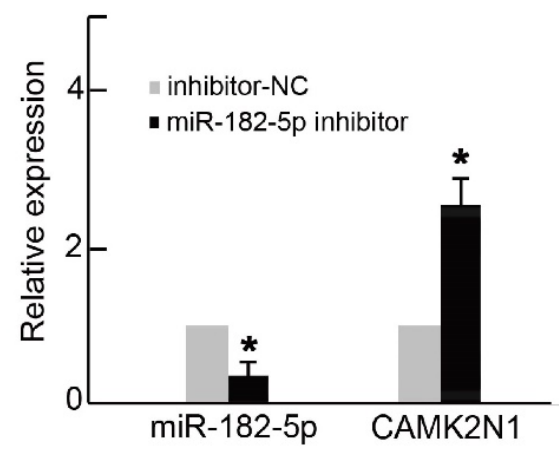

Fig. 7. miR-182-5p suppresses tumor growth in vivo by targeting CAMK2N1. Tumor volume of CAL-27 cell tumor-bearing BALB/c mice in the miR-182-5p-inhibitor and miR-NC groups (A). Mice were sacrificed and the tumors were excised, photographed (B), and weighed (C) at 21 days after injection. mRNA (D) and protein (E) levels of CAMK2N1 in the tumors were measured by qRT-PCR and western blotting, respectively. Data are presented as the mean \pm SD of three independent experiments. ${ }^{*} \mathrm{p}<0.05$ vs. the other group.

\section{Discussion}

OSCC is a highly prevalent cancer worldwide, especially in developing regions such as Southeast China [16]. Current research has been looking into potential biomarkers and new therapeutic agents for OSCC. Our study provides evidence that miR-182-5p augments OSCC cell proliferation by modulating CAMK2N1 expression. We demonstrated that miR-182-5p dysregulation is a central factor in OSCC pathogenesis through its proliferation-enhancing effects.

miRNAs are RNA molecules of approximately 22 nucleotides in length that bind to the 3 '-UTR region of their respective target genes and exert their influence on gene expression 
by either inhibiting protein translation or degrading mRNA. miRNAs are known to be an integral component of cancer development [17-19]. Several studies have highlighted the role of miR-182-5p in the development of different cancers [13, 14]. In glioblastoma, miR182-5p targets protein phosphatase 1 regulatory inhibitor subunit 1C [20]. miR-182-5p promotes the progression of hepatocellular carcinoma by repressing FOXO3a expression [21]. By down-regulating RAB27A expression, miR-182-5p improves the migration, mitosis, viability, and invasion capabilities of human gastric cancer cells [22]. Inhibiting miR-182$5 p$ by regulating CASP9 expression confers pro-apoptotic and anti-proliferative effects in human breast cancer [23]. Activated STAT3 induces miR-182-5p expression, which has been found to enhance the growth of glioma tumors [24]. Our study is the first to outline a role for miR-182-5p in the proliferation of OSCC cells.

The CAMK2N1 gene, a calcium/calmodulin-dependent protein kinase II inhibitor, is a known potent modulator of tumorigenesis and subsequent tumor growth [15]. CAMK2N1 expression may have a tumor suppressing role in certain cancers, and its dysregulation has been linked to tumorigenesis [25]. CAMK2N1 halts the progression of prostate cancer by interacting with androgen receptor signaling pathways [25]. Furthermore, in castrationresistant prostate cancer, CAMK2N1 may have a tumor suppressive role [26]. Nevertheless, data regarding the interactions of miRNAs with CAMK2N1 are scarce. In this study, CAMK2N1 was discovered to be directly downstream from miR-182-5p, as evidenced by luciferase assay data. Dysfunctional miR-182-5p expression was rescued by CAMK2N1 re-expression. Taken together, our findings indicate that CAMK2N1 is regulated by miR-182-5p to drive the proliferation of OSCC cells.

\section{Conclusion}

In summary, miR-182-5p plays a vital role in controlling OSCC cell apoptosis and proliferation by regulating CAMK2N1 expression, which was found to be reduced in OSCC. Down-regulation of miR-182-5p expression attenuated tumor growth, cell survival, and proliferation in vivo through the regulation of the AKT/ERK1/2/NF- $\mathrm{B}$ signaling pathways. With these findings, we gain a better understanding of the molecular mechanisms underlying the progression of OSCC and propose miR-182-5p as a future biomarker and novel therapeutic target for OSCC.

\section{Acknowledgements}

Supported by Shenzhen science and technology research and development fund (JCYJ20160422154812784).

\section{Disclosure Statement}

The authors declare that no conflict of interest exists.

\section{References}

1 Nagai H, Hasegawa S, Uchida F, Terabe T, Ishibashi Kanno N, Kato K, Yamagata K, Sakai S, Kawashiri S, Sato H, Yanagawa T, Bukawa H: MicroRNA-205-5p suppresses the invasiveness of oral squamous cell carcinoma by inhibiting TIMP-2 expression. Int J Oncol 2018;52:841-850.

2 Desai K, Kale A: Immunoexpression of programmed cell death 4 protein in normal oral mucosa, oral epithelial dysplasia and oral squamous cell carcinoma. J Oral Maxillofac Pathol 2017;21:462-473. 


\section{Cellular Physiology Cell Physiol Biochem 2018:49:1329-1341 \begin{tabular}{l|l} 
and Biochemistry & DOI: 10.1159/000493411 \\
(c) 2018 The Author(s). Published by S. Karger AG, Basel \\
www.karger.com/cpb
\end{tabular}

3 Padma R, Kalaivani A, Sundaresan S, Sathish P: The relationship between histological differentiation and disease recurrence of primary oral squamous cell carcinoma. J Oral Maxillofac Pathol 2017;21:461.

- 4 Fang C, Wu C, Chen P, Chang Y, Chuang C, Lai C, Yang S, Tsai L: Antimetastatic potentials of salvianolic acid A on oral squamous cell carcinoma by targeting MMP-2 and the c-Raf/MEK/ERK pathway. Environ Toxicol 2018;33:545-554.

5 Chuerduangphui J, Ekalaksananan T, Chaiyarit P, Patarapadungkit N, Chotiyano A, Kongyingyoes B, Promthet S, Pientong C: Effects of arecoline on proliferation of oral squamous cell carcinoma cells by dysregulating c-Myc and miR-22, directly targeting oncostatin M. PloS One 2018;13:e0192009.

-6 Yanamoto S, Umeda M, Kioi M, Kirita T, Yamashita T, Hiratsuka H, Yokoo S, Tanzawa H, Uzawa N, Shibahara T, Ota Y, Kurita H, Okura M, Hamakawa H, Kusukawa J, Tohnai I: Multicenter retrospective study of cetuximab plus platinum-based chemotherapy for recurrent or metastatic oral squamous cell carcinoma. Cancer Chemother Pharmacol 2018;81:549-554.

7 Keerthi R, Dutta A, Agarwal S, Kani V, Khatua A: Perineural Invasion of Oral Squamous Cell Carcinoma: A New Hurdle for Surgeons. J Maxillofac Oral Surg 2018;17:59-63.

8 Shukla NK, Deo SVS, Jakhetiya A, Nml M, Sreenivas V, Thulkar S, Bhasker S, Sharma A: Clinical Spectrum, Treatment and Relapse Patterns in 353 Patients with Squamous Cell Carcinoma of the Alveobuccal Complex Treated with a Curative Intent: A Retrospective Study. J Maxillofac Oral Surg 2018;17:24-31.

-9 Arunkumar G, Deva Magendhra Rao AK, Manikandan M, Prasanna Srinivasa Rao H, Subbiah S, Ilangovan R, Murugan AK, Munirajan AK: Dysregulation of miR-200 family microRNAs and epithelial-mesenchymal transition markers in oral squamous cell carcinoma. Oncol Lett 2018;15:649-657.

10 Lee R, Feinbaum R, Ambros V: The C. elegans heterochronic gene lin-4 encodes small RNAs with antisense complementarity to lin-14. Cell 1993;75:843-854.

-11 O’Shea J, Holland S, Staudt L: JAKs and STATs in immunity, immunodeficiency, and cancer. N Engl J Med 2013;368:161-170.

12 Lai YH, Liu H, Chiang WF, Chen TW, Chu LJ, Yu JS, Chen SJ, Chen HC, Tan BC: MiR-31-5p-ACOX1 Axis Enhances Tumorigenic Fitness in Oral Squamous Cell Carcinoma Via the Promigratory Prostaglandin E2. Theranostics 2018;8:486-504.

13 Liu MD, Wu H, Wang S, Pang P, Jin S, Sun CF, Liu FY: MiR-1275 promotes cell migration, invasion and proliferation in squamous cell carcinoma of head and neck via up-regulating IGF-1R and CCR7. Gene 2018;646:1-7.

14 Arya D, Sachithanandan S, Ross C, Palakodeti D, Li S, Krishna S: MiRNA182 regulates percentage of myeloid and erythroid cells in chronic myeloid leukemia. Cell Death Dis 2017;8:e2547.

15 Hafner N, Steinbach D, Jansen L, Diebolder H, Durst M, Runnebaum IB: RUNX3 and CAMK2N1 hypermethylation as prognostic marker for epithelial ovarian cancer. Int J Cancer 2016;138:217-228.

-16 Weng J, Dokla E, Bai L, Chen C, Chiu S, Shieh T: A 5’ AMP-Activated Protein Kinase Enzyme Activator, Compound 59, Induces Autophagy and Apoptosis in Human Oral Squamous Cell Carcinoma. Basic Clin Pharmacol Toxicol 2018;123:21-29.

17 Patel N, Garikapati KR, Makani VKK, Nair AD, Vangara N, Bhadra U, Pal Bhadra M: Regulating BMI1 expression via miRNAs promote Mesenchymal to Epithelial Transition (MET) and sensitizes breast cancer cell to chemotherapeutic drug. PLoS One 2018;13:e0190245.

18 Maolakuerban N, Azhati B, Tusong H, Abula A, Yasheng A, Xireyazidan A: MiR-200c-3p inhibits cell migration and invasion of clear cell renal cell carcinoma via regulating SLC6A1. Cancer Biol Ther 2018;19:282-291.

19 Zhang B, Li Y, Hou D, Shi Q Yang S, Li Q: MicroRNA-375 Inhibits Growth and Enhances Radiosensitivity in Oral Squamous Cell Carcinoma by Targeting Insulin Like Growth Factor 1 Receptor. Cell Physiol Biochem 2017;42:2105-2117.

20 Liu L, Zhang X, Nan C, Zhao Z, Ma S, Li W, Hu H, Liang Z: MicroRNA-182 targets protein phosphatase 1 regulatory inhibitor subunit $1 \mathrm{C}$ in glioblastoma. Oncotarget 2017;8:114677-114684.

21 Cao M, You A, Zhu X, Zhang W, Zhang Y, Zhang S, Zhang K, Cai H, Shi W, Li X, Li K, Gao D, Ma D, Ye B, Wang C, Qin C, Sun H, Zhang T, Tang Z: miR-182-5p promotes hepatocellular carcinoma progression by repressing FOXO3a. J Hematol Oncol 2018;11:12.

22 Li Y, Chen S, Shan Z, Bi L, Yu S, Li Y, Xu S: miR-182-5p improves the viability, mitosis, migration, and invasion ability of human gastric cancer cells by down-regulating RAB27A. Biosci Rep 2017;37. 


\section{Cellular Physiology Cell Physiol Biochem 2018;49:1329-1341 \begin{tabular}{l|l|l} 
DOI: 10.1159/000493411 & $\begin{array}{l}\text { O 2018 The Author(s). Published by S. Karger AG, Basel } \\
\text { www.karger.com/cpb }\end{array}$
\end{tabular}}

Li et al.: miR-182-5p Promotes Growth by Inhibiting CAMK2N1

-23 Sharifi M, Moridnia A: Apoptosis-inducing and antiproliferative effect by inhibition of miR-182-5p through the regulation of CASP9 expression in human breast cancer. Cancer Gene Ther 2017;24:75-82.

24 Xue J, Zhou A, Wu Y, Morris SA, Lin K, Amin S, Verhaak R, Fuller G, Xie K, Heimberger AB, Huang S: miR-1825p Induced by STAT3 Activation Promotes Glioma Tumorigenesis. Cancer Res 2016;76:4293-4304.

-25 Wang T, Guo S, Liu Z, Wu L, Li M, Yang J, Chen R, Liu X, Xu H, Cai S, Chen H, Li W, Xu S, Wang L, Hu Z, Zhuang Q, Wang L, Wu K, Liu J, Ye Z, Ji JY, et al.: CAMK2N1 inhibits prostate cancer progression through androgen receptor-dependent signaling. Oncotarget 2014;5:10293-10306.

-26 Wang T, Liu Z, Guo S, Wu L, Li M, Yang J, Chen R, Xu H, Cai S, Chen H, Li W, Wang L, Hu Z, Zhuang Q, Xu S, Wang L, Liu J, Ye Z, Ji JY, Wang C, Chen K: The tumor suppressive role of CAMK2N1 in castration-resistant prostate cancer. Oncotarget 2014;5:3611-3621. 